\title{
Cartilage Restoration of Bipolar Lesions Within the Patellofemoral Joint Delays Need for Arthroplasty: A Systematic Review of Rates of Failure
}

\author{
Anirudh K. Gowd, M.D., Alexander E. Weimer, B.S., Danielle E. Rider, B.S., \\ Edward C. Beck, M.D., M.P.H., Avinesh Agarwalla, M.D., Lisa K. O’Brien, D.O., \\ Michael J. Alaia, M.D., Cristin M. Ferguson, M.D., and Brian R. Waterman, M.D.
}

\begin{abstract}
Purpose: The purpose of the present review is to systematically review the available literature for failure rates and complications of cartilage restoration of bipolar chondral defects in the patellofemoral (PF) joint to assess the ability to treat these lesions without arthroplasty. Methods: PubMed and MEDLINE databases were queried between 2000 to 2020 using the keywords "osteochondral" and "knee" and "microfracture," "autologous chondrocyte implantation (ACI)," or "transplantation." Patient selection included patients with bipolar chondral lesions of the patellofemoral joint that were treated with cartilage restoration procedures. Treatment of PF joints were reviewed for surgical indications/technique, rates of failure, defect characteristics, and time to failure. For the purposes of this study, failure was defined by each individual author on their respective studies. Results: After screening 1,295 articles, there were 8 publications analyzed quantitatively and 10 articles analyzed both quantitatively and qualitatively. A total of 249 knees involved bipolar lesions of the patellofemoral joint. The weighted average age was $36.5 \pm 10.4$ years, and weighted average follow-up was $89.0 \pm 31.7$ months. There were failures in $0 \%$ to $50 \%$ of cases, revision procedures in $0 \%$ to $10 \%$ of cases, conversion to arthroplasty in in $0 \%$ to $50 \%$ of cases, and unsatisfactory outcome without revision in $0 \%$ to $8.3 \%$ of cases. The range in average failure rate was $0 \%$ to $50.0 \%\left(\mathrm{I}^{2}=68.0 \%\right)$, whereas the range in average time to failure was 2.9 to 6.8 years $\left(\mathrm{I}^{2}=79.0 \%\right)$. Conclusion: From the available data, established cartilage restoration procedures may provide favorable patient-reported function, avoidance of secondary surgery, and joint preservation in at least $80 \%$ of patients at short- to mid-term follow-up. Level of Evidence: Level IV, systematic review of Level IV studies.
\end{abstract}

$\mathbf{T}$ he patellofemoral (PF) joint maintains a high carrying load that can reach up to 7.8 times that of body weight during daily physiological activities such as

From the Wake Forest University Baptist Medical Center (A.K.G., A.E.W., D.E.R., E.C.B., L.K.O., C.M.F., B.R.W.), Winston-Salem, North Carolina; Westchester Medical Center (A.A.), Valhalla, New York; and New York University Langone Health (M.J.A.), New York, New York, U.S.A.

The authors report the following potential conflicts of interest or sources of funding: M.J.A. reports personal fees from Arthrex, Inc.; C.M.F reports grants from Arthrex, Inc., Anika, and Zimmer; B.R.W. reports personal fees from Arthrex, Inc., Elsevier, FH Ortho, Kaliber AI, Sparta Science, Varicel, and Vivorte. Full ICMJE author disclosure forms are available for this article online, as supplementary material.

Received July 5, 2020; accepted February 10, 2021.

Address correspondence to Anirudh K. Gowd, M.D., Department of Orthopedic Surgery, Wake Forest University Baptist Medical Center, 2244 King George Ct., Winston-Salem, NC 27103,U.S.A. E-mail: anirudhkgowd@ gmail.com

(C) 2021 THE AUTHORS. Published by Elsevier Inc. on behalf of the Arthroscopy Association of North America. This is an open access article under the CC BY-NC-ND license (http://creativecommons.org/licenses/by-nc-nd/4.0/). 2666-061X/201057

https://doi.org/10.1016/j.asmr.2021.02.001 the deep knee bend or squatting. ${ }^{1}$ As a result of this high carrying load, the PF articulation experiences unique loading patterns and exposure to shear stresses with rotational moments about the knee, which often leads to cartilage pathology developing within the PF joint. ${ }^{2}$ These stresses may be further exacerbated by selected patient-specific anatomic risk factors, such as patella alta, rotational malalignment, trochlea hypoplasia, and tissue hyperlaxity. Bipolar, or so-called "kissing," lesions of the PF joint represent a subset of patients with advanced pathology resulting in reciprocal cartilage defects of the patella and trochlea., Cartilage restoration has been shown to be an efficacious treatment in suitable patients for cartilage lesions in the $\mathrm{PF}$ joint ${ }^{5}$; however, there are limited data on comprehensive surgical outcomes with treatment of bipolar PF lesions.

Treatment of chondral lesions of the PF joint can often be challenging because of the high stress borne by the compartment. Furthermore, patellar maltracking that is attributable to patella alta, ligamentous 
instability, or limb alignment, further complicates treatment modalities. If left untreated, patients with focal defects of the PF joint may potentially have progression or peripheral expansion of cartilage damage, with increasing pathologic loading of the underlying subchondral bone and advancement toward early-stage arthritis. ${ }^{6}$ With early arthritis, there may multicompartment involvement, and the cytokinetic process of cartilage degeneration may no longer be reversible. $^{7}$

In response to this possible sequela, cartilage restoration and joint preservation techniques, such as osteochondral allograft (OCA) and autologous chondrocyte implantation (ACI), have become increasingly used for treatment of large patellofemoral chondral defects in the knee. ${ }^{8}$ Under previous historical algorithms, $^{9-11}$ bipolar lesions have traditionally been considered a relative contraindication for cartilage restoration. However, with advancement of surgical techniques, numerous reports have suggested guarded optimism with cartilage restoration of bipolar chondral defects in order to improve function and potentially delay the need for arthroplasty. ${ }^{12-21}$ The purpose of this study is to systematically review the available literature for failure rates and complications of cartilage restoration of bipolar chondral defects in the PF joint to assess the ability to treat these lesions without use of arthroplasty. The hypothesis is that operative intervention via either OCA or ACI maintain failure rates less than $20 \%$ and therefore are feasible options for the management of bipolar patellofemoral lesions in well-selected patients.

\section{Methods}

\section{Search Strategy}

PubMed and MEDLINE databases were queried between 2000 to 2020 using the PRISMA (Preferred Reporting Items for Systematic Reviews and Metaanalyses) guidelines. The keywords used for the search were: "osteochondral" and "knee" and "microfracture" and "autologous chondrocyte implantation" or "transplantation." An initial search was performed on November 17, 2019, and then reviewed on March 1, 2020, for new articles. References of included articles were also reviewed to determine eligibility of inclusion.

\section{Selection Criteria}

Articles were included if a subset of the population examined bipolar lesions; in these cases, data were extracted to include only outcomes regarding bipolar PF pathology. Articles were reviewed to ensure that lesions were reciprocal on the patella and trochlea, rather than multifocal. Nonhuman studies and non-English studies were excluded. Articles were not excluded by study design.

\section{Quality Evaluation}

No randomized clinical trials were available for review. As such, the Methodological Index for Non-Randomized Studies (MINORS) checklist was used to evaluate the quality of nonrandomized studies. ${ }^{22}$ This checklist involved a 12-item survey, 4 of which are applicable to comparative studies only. Scoring was on a scale from 0 to 2 where $0=$ not reported, $1=$ reported but poorly done and/or inadequate, and $2=$ reported well and adequately done. Noncomparative studies had a maximum score of 16, whereas comparison studies had a maximum score of 24. Each study included was scored by 2 authors (D.R. and A.E.W.), and a third reviewer was used (A.K.G.) if there was a disagreement.

\section{Data Extraction}

Articles that were deemed eligible based on inclusion/ exclusion criteria were reviewed for the following information: study design, patient demographics, followup period, osteochondral defect size, surgical technique, rate of failure, and time to failure. Each article was qualitatively analyzed for definition of failure as defined by each individual author. Subsequently, information regarding rate of revision restoration procedure, proportion of concomitant procedures, rate of conversion to arthroplasty, and poor clinical outcome was tabulated as author definitions of failure were variable.

\section{Statistical Analysis}

RStudio software version 1.0.143 (R Foundation for Statistical Computing) was used for statistical analysis. The rate of failure was the primary outcome collected, as determined by procedure performed. Secondary outcomes were time to failure, rate of revision restoration procedure, rate of conversion to arthroplasty, rate of poor clinical outcome, and varying indications for treatment. These outcomes were graphically represented using forest plots and the $\mathrm{I}^{2}$ value was used for heterogeneity. The DerSimonian-Laird estimator was used to determine treatment effect sizes. ${ }^{23}$ A random effects model was used because there was a high level of expected heterogeneity. Articles were inherently heterogeneous because of slightly varying indications for surgery, different surgeries performed, varying rates of concomitant procedure, and varying levels of pathology. Publication bias was evaluated using a funnel chart. The treatment effect was plotted on the xaxis, whereas the size of each study was plotted on the $\mathrm{y}$-axis. Point estimates were checked to be distributed evenly and symmetrically around the real effect of treatment to determine if no bias existed by Egger's test for asymmetry. ${ }^{24}$

\section{Results}

The initial search query yielded 1,295 articles. Following inclusion/exclusion criteria, there were 8 
Fig 1. Preferred reporting items for systematic reviews and meta-analyses diagram of included articles available for analysis regarding bipolar lesions in the knee.
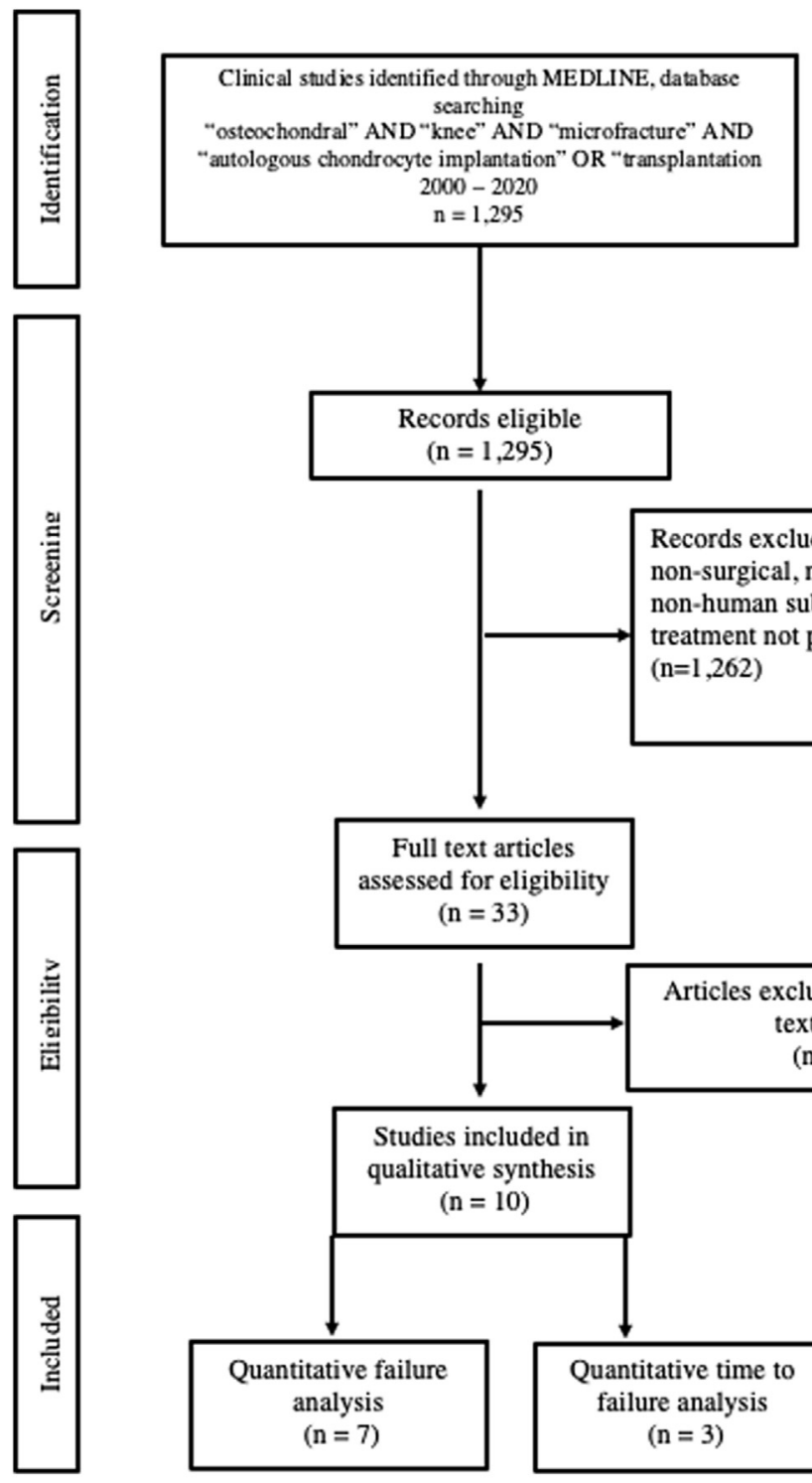

Full text articles assessed for eligibility $(n=33)$

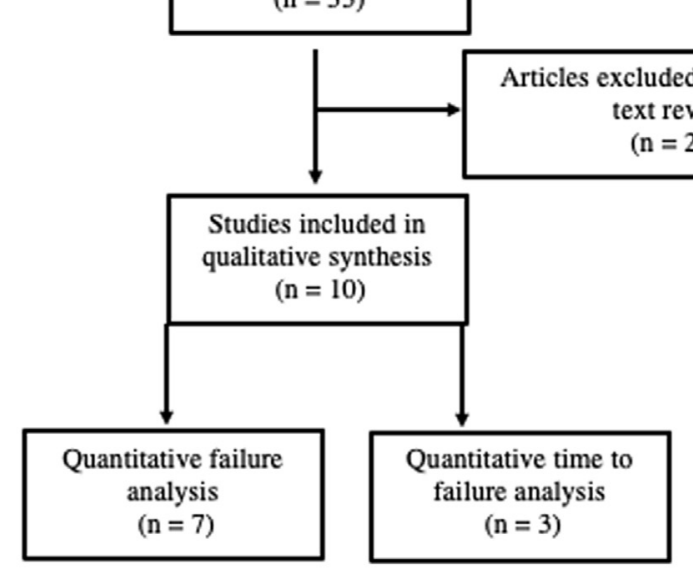

Records excluded due to non-English, non-surgical, no reported outcomes, non-human subjects, efficacy of treatment not primary purpose $(\mathrm{n}=1,262)$ publications available for quantitative analysis and a total of 10 articles for both quantitative and qualitative analysis (Fig 1). In total, there were 559 knees; however, only 237 knees involved bipolar lesions of the patellofemoral joint. The weighted average age was $36.5 \pm 10.4$ years (14-74 years) and weighted average follow-up was $89.0 \pm 31.7$ months (6-236 months). All studies were classified as retrospective case series (Level of Evidence IV). The range in MINORS criteria was 10.0 to 16.0. Demographic information is summarized in Table 1. Publication bias was assessed via funnel plot, which demonstrates symmetric alignment of treatment effect size failure rates $(P=.076)$ (Fig 2).

Concomitant procedures were routinely performed with cartilage restoration; however, most articles lacked the granularity to indicate which procedures were performed with bipolar procedures. Indications for treatment and concomitant procedures are also summarized in Table 2. Most commonly performed procedures within this cohort were tibial tubercle osteotomy $(n=86)$, lateral retinacular release $(n=55)$, and high tibial osteotomy $(\mathrm{n}=53)$. Only 3 articles reported the average lesion sizes in identified patients with bipolar defects. Yabumoto et al. $^{20}$ performed osteochondral autograft transplantation (OATs) and thereby reported smaller lesions $\left(1.0-7.5 \mathrm{~cm}^{2}\right.$ for trochlear and $1.0-2.25 \mathrm{~cm}^{2}$ for patellar). The reported range in reported lesion size in the other 2 studies was 5.6 to $7.1 \mathrm{~cm}^{2}\left(5.3 \pm 2.7 \mathrm{~cm}^{2}\right)$ for patellar lesions and 4.2 to $13.2 \mathrm{~cm}^{2}\left(5.2 \pm 2.9 \mathrm{~cm}^{2}\right)$ for trochlea lesions. ${ }^{12,17}$

Operative treatments and surgical techniques for bipolar chondral restoration varied widely. Four articles investigated fresh OCA, whereas five articles investigated ACI. One article investigated OATs from nonweightbearing 
Table I. Demographic Characteristics of Included Studies Regarding Operative Management of Bipolar Defects in the Knee

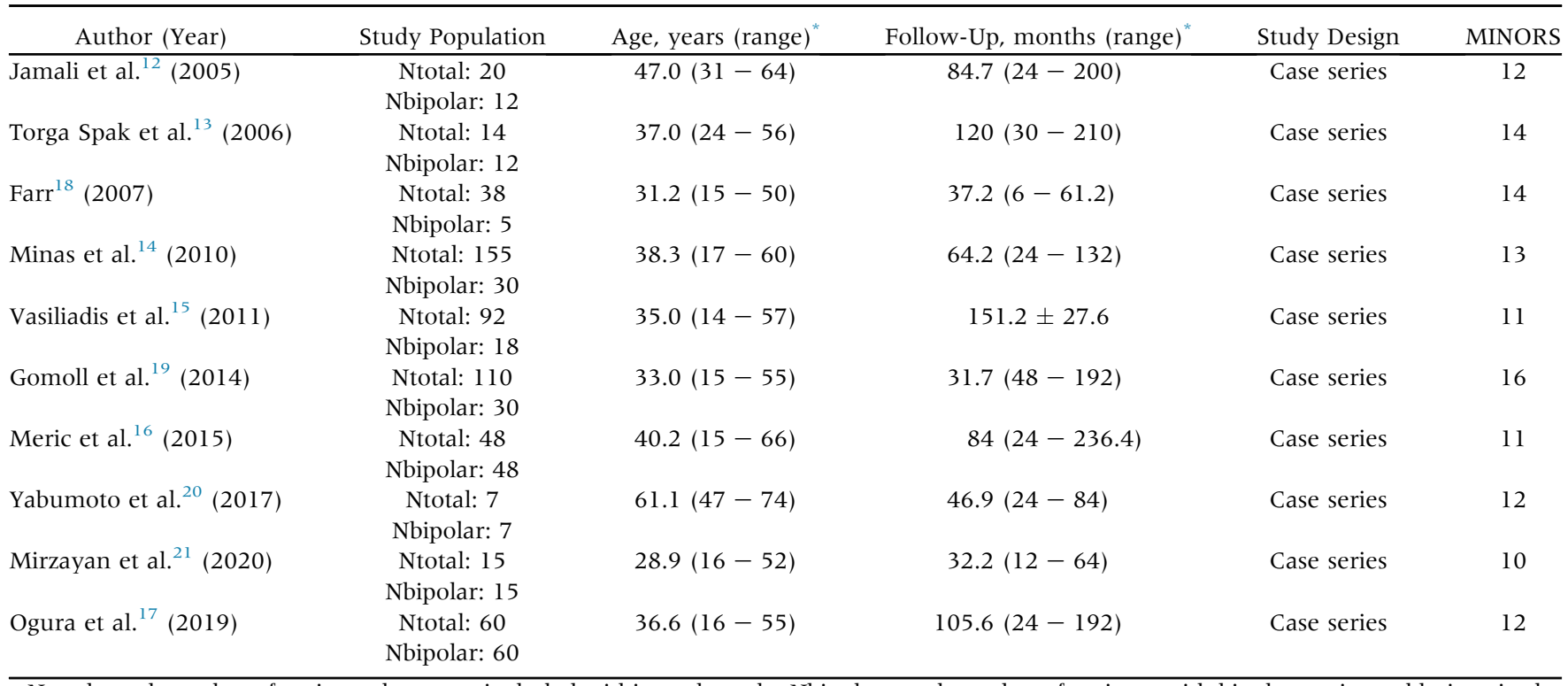

Ntotal, total number of patients that were included within each study; Nbipolar, total number of patients with bipolar, reciprocal lesions in the patellofemoral compartment represented within each study.

*In reference to the total article because demographic information was not subdivided by bipolar patients.

areas. $^{20}$ Four articles used first-generation ACI with periosteum transplantation, ${ }^{14,15,18,19}$ whereas 1 article used a combination of both first-generation ACI with periosteum transplantation and second-generation ACI with type I/III porcine bilayer collagen membrane. ${ }^{17}$

Failure definitions and study conclusions are summarized in Table 3. There were failures in between $0 \%$ to $50 \%$ of cases. A revision cartilage restoration procedure (either ACI or OCA) was performed $0 \%$ to $10 \%$ of cases. Between $0 \%$ to $50 \%$ of patients were converted to either patellofemoral or total knee arthroplasty. Last, $0 \%$ to $8.3 \%$ of patients had an unsatisfactory clinical outcome based on continued symptoms but did not undergo revision procedure or conversion to arthroplasty. The range in average failure rate was $0 \%$ to $50.0 \%\left(\mathrm{I}^{2}=68.0 \%\right)$. By procedure, the range in average failure rate was $0.0 \%$ to $33.3 \%$ $\left(\mathrm{I}^{2}=80.9 \%\right)$ for OCA and $6.7 \%$ to $50.0 \%\left(\mathrm{I}^{2}=33.1 \%\right)$ for ACI. Three articles reported time to failure in years. ${ }^{12,13,17}$ The range in average time to failure was

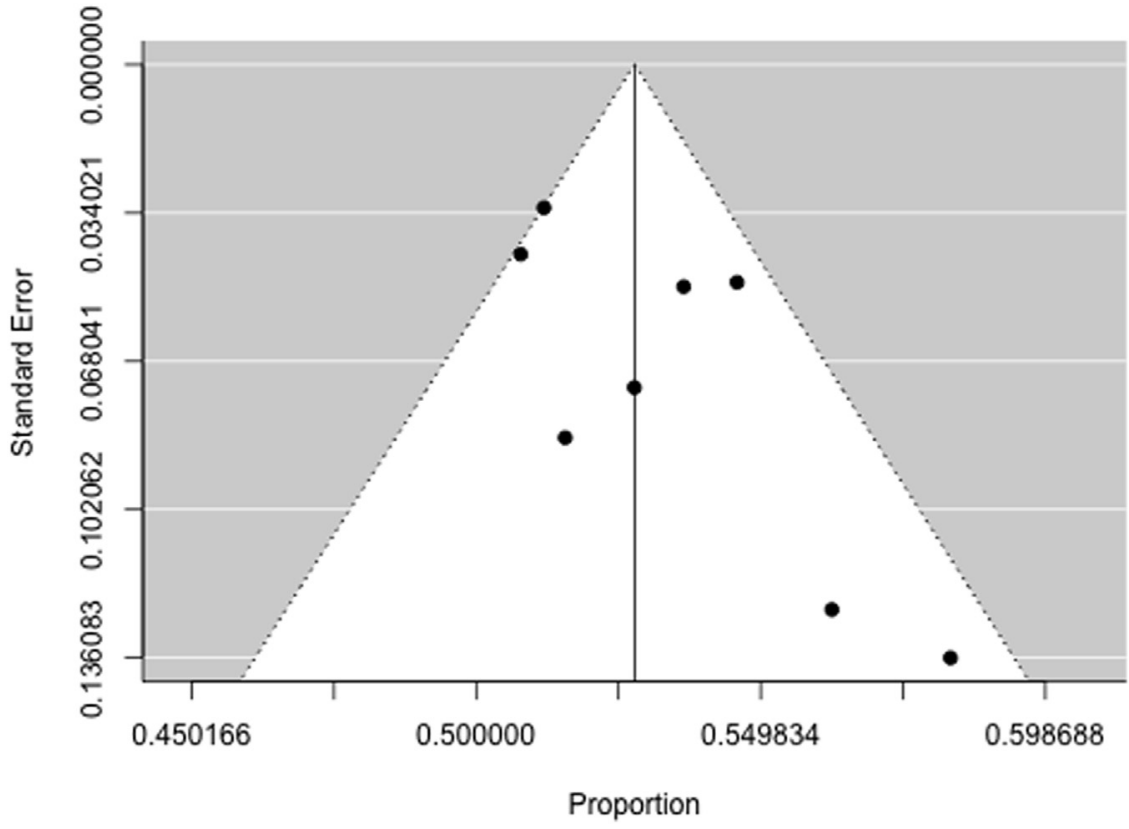

Fig 2. Funnel plot demonstrating publication bias in articles examining failure rates following treatment of bipolar cartilage defects. The treatment effect (failure rate) was plotted on the $\mathrm{x}$-axis, while the size of each study was plotted on the y-axis. 
Table 2. Procedural Characteristics of Included Articles Regarding Management of Bipolar Lesions

\begin{tabular}{|c|c|c|c|c|}
\hline Author (Year) & $\begin{array}{c}\text { Lesion } \\
\text { Location }(\mathrm{N})\end{array}$ & Procedure & Concomitant Procedures $(\mathrm{N})$ & Indications for Surgery \\
\hline Jamali et al. $^{12}(2005)$ & $\mathrm{PF}(12)$ & OCA & Lat RR (9) & $\begin{array}{l}\text { Unspecified, presence of PF } \\
\text { arthritis receiving OCA }\end{array}$ \\
\hline Farr $^{18}(2007)$ & PF (5) & $\mathrm{ACI}(\mathrm{P}-\mathrm{ACI})$ & $\begin{array}{l}\text { TTO (28), MAT (1), Lat RR (2), } \\
\text { ACLR (1), MPFL (1), medial } \\
\text { release (1), scar debridement } \\
\text { (1) }\end{array}$ & $\begin{array}{l}\text { Unspecified, ICRS } 3 \text { or } 4 \text { that } \\
\text { received ACI }\end{array}$ \\
\hline Minas et al. ${ }^{14}(2010)$ & PF (30) & ACI (P-ACI) & $\begin{array}{l}\text { HTO }(47) \\
\text { TTO (44) } \\
\text { MAT (7) } \\
\text { Ligament }(4) \\
\text { DFO }(1)^{*}\end{array}$ & $\begin{array}{l}\text { Outerbridge III-IV, }<50 \% \text { joint } \\
\text { space loss on radiograph }\end{array}$ \\
\hline Vasiliadis et al. ${ }^{15}$ (2011) & PF (18) & ACI (P-ACI) & $\begin{array}{l}\text { Unspecified realignment (38) } \\
\text { Unspecified extensor } \\
\text { mechanism }(22)^{*}\end{array}$ & $\begin{array}{l}\text { Unspecified, consecutive patients } \\
\text { with full-thickness cartilage } \\
\text { lesions treated with ACI }\end{array}$ \\
\hline Meric et al. ${ }^{16}(2015)$ & PF (14) & OCA & $\begin{array}{l}\text { HWR (9) } \\
\text { RR (7) } \\
\text { Meniscectomy (2) } \\
\text { Lateral imbrication (1) } \\
\text { HTO (1) } \\
\text { DFO (1) }\end{array}$ & $\begin{array}{l}\text { Unspecified, included reciprocal } \\
\text { lesions in patellofemoral or } \\
\text { tibiofemoral joint, ICRS III/IV, } \\
\text { patients who failed other } \\
\text { therapies }\end{array}$ \\
\hline Yabumoto et al. ${ }^{20}$ (2017) & PF (7) & OATS & None & $\begin{array}{l}\text { Isolated ICRS } 3 \text { or } 4 \text { in PF joint } \\
\text { without malalignment }\end{array}$ \\
\hline Mirzayan et al. ${ }^{21}(2020)$ & PF (15) & OCA & $\begin{array}{l}\text { MPFL (11) } \\
\text { TTO (1) }\end{array}$ & $\begin{array}{l}\text { Patients with III/IV lesions on PF } \\
\text { joint, who declined PF } \\
\text { arthroplasty }\end{array}$ \\
\hline
\end{tabular}

P-ACI, periosteum-ACI; C-ACI, collagen membrane-ACI; RR, retinacular release; HTO, high tibial osteotomy; DFO, distal femoral osteotomy; VMO, vastus medialis oblique; MAT, meniscus allograft transplantation; MPFL, medial patellofemoral ligament.

*Concomitant procedures were not separated by bipolar lesions.

2.9 to 6.8 years $\left(\mathrm{I}^{2}=79.0 \%\right)$. Failures and time to failure are summarized in Figures 3 and 4, respectively.

\section{Discussion}

Classically, cartilage restoration of bipolar lesions involving the patellofemoral joint have been viewed as salvage procedures in patients not suitable for arthroplasty. However, findings from the present study suggest that restorative procedures for these patients may be viable options for preserving function and delaying secondary surgery. From the available published series, failure of these treatments was observed in less than half of patients, and when present, delayed arthroplasty by a mean of 2.8 to 6.8 years. Furthermore, there was a high prevalence of concomitant realignment and soft tissue procedures that likely contributed to the high success rate of operation. Given the summary of these findings, treatment of bipolar lesions within the PF joint should be considered as a treatment option in suitable candidates.

Patient selection for treatment of bipolar lesions remains challenging. Treatment with either OCA or ACI is reserved for medium to large, high-grade cartilage lesions. Specifically in treatment of patellofemoral bipolar lesions, studies have indicated a requirement for $>50 \%$ joint space preservation on dedicated 
Table 3. Definitions of failure and conclusions from included studies

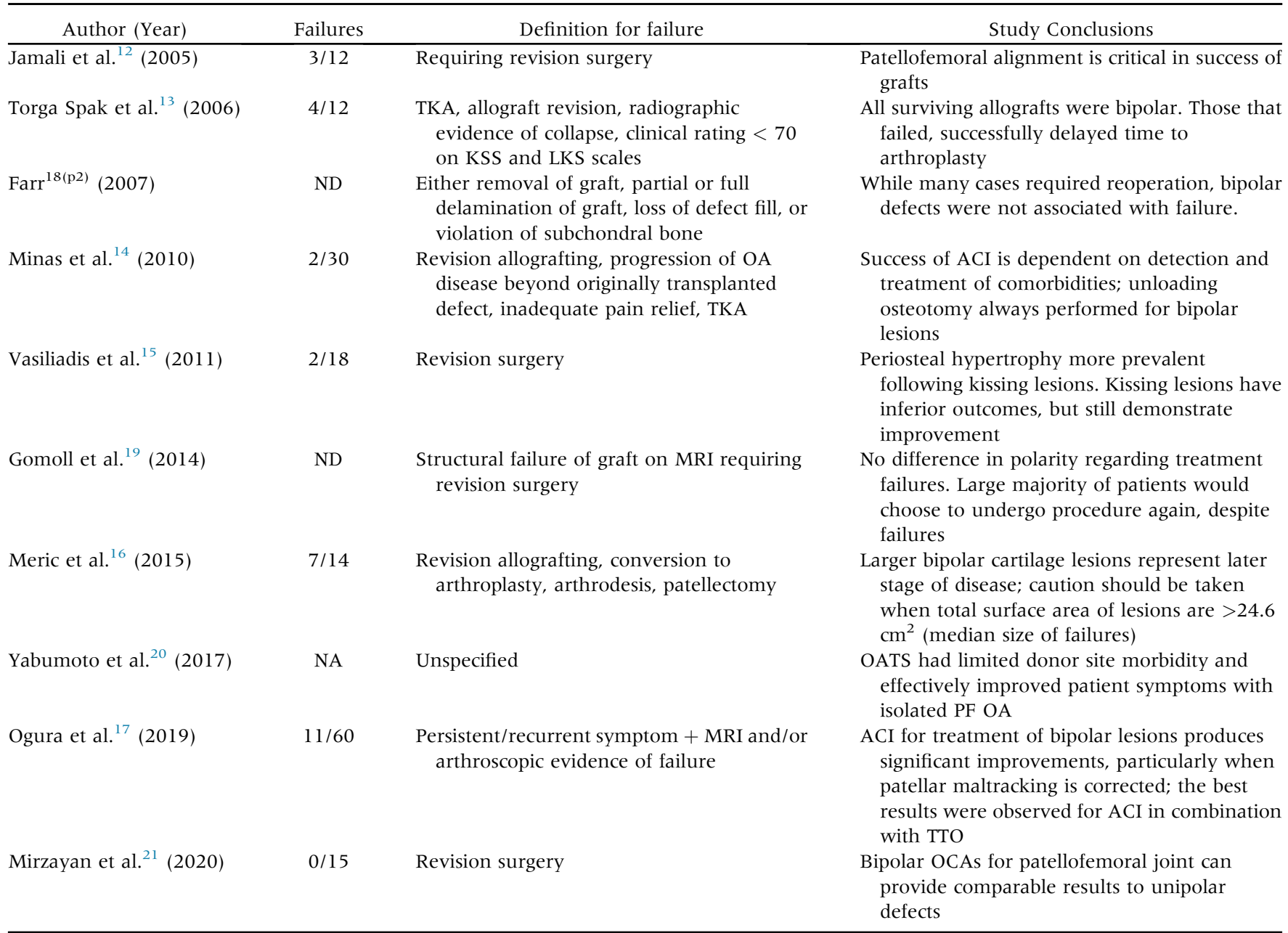

TKA, total knee arthroplasty; KSS, Knee Society System; LKS, Lysholm Knee Score; OA, osteoarthritis; ND, not differentiated; MRI, magnetic resonance imaging; NA, not application.

radiographic imaging. ${ }^{4,14}$ Age also serves as a primary consideration, as younger (i.e., <50 years), and more active patients are less likely to be suitable candidates for arthroplasty. Interestingly, Niemeyer et al. ${ }^{25}$ noted that increasing preoperative athletic activity may place greater stress on the patellofemoral joint and correlate with heightened expectations after surgery, which may hinder their chance at a successful outcome. From a series involving military service members, Zarkadis et al. ${ }^{26}$ corroborated these findings, indicating that patients younger than 30 years of age were more likely to fail patellofemoral ACI, although there was no adverse association with bipolar defects. Melugin et al. ${ }^{27}$ similarly reviewed bipolar lesions in both tibiofemoral and patellofemoral compartments and found cartilage restoration to be safe options with a low rate of major complications. Overall, included articles did not delineate strict indications for treatment for bipolar PF lesions, which indicates that the decision to proceed with surgery in these patients is complicated, multifactorial, and must be performed on a case-by-case basis.

Correction of patellar maltracking has been shown to have a significant effect on graft success. Patellar maltracking predisposes the $\mathrm{PF}$ joint to abnormal shear forces that preclude early graft incorporation and further remodeling, particularly with cell-based treatments. $^{28,29}$ An expert panel on cartilage restoration deemed concurrent correction of anatomic abnormalities to be of paramount importance during the cartilage restoration procedure. ${ }^{30}$ The biomechanical literature has demonstrated that unloading procedures, such as tibial tubercle osteotomy (TTO) can reduce joint surface pressures by up to $30 \% .^{28,29}$ Literature examining unipolar chondral defects have demonstrated improved reported outcomes when realignment osteotomy was performed. $^{31,32}$ However, Peterson and co-authors noted that patellofemoral lesions had comparable patient outcomes following ACI whether or not 


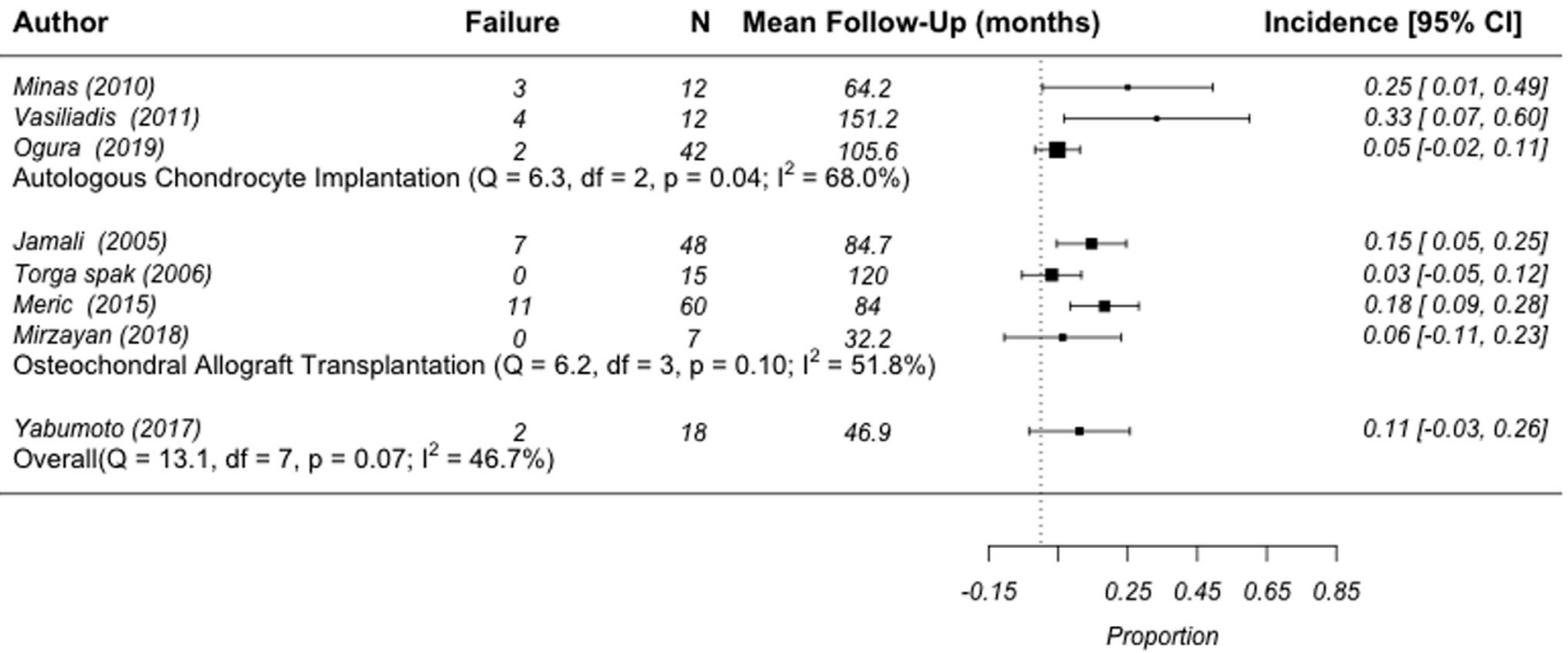

Fig 3. Incidence of failure by procedure of operative management bipolar patellofemoral lesions. Definitions of failure were dependent on each individual author. N, total number of bipolar cases; Q, Cochran's Q-statistic for heterogeneity; df, degrees of freedom; $\mathrm{p}$, statistical significance test for heterogeneity; $\mathrm{I}^{2}$, measure of heterogeneity.

realignment surgery was also performed. ${ }^{33}$ Included articles had a high prevalence of realignment and patellar maltracking procedures through soft tissue release, osteotomy, and medial patellofemoral ligament reconstruction that help explain the low rate of failures despite the high level of pathology. Yet, Ogura et al ${ }^{17}$ found no statistically significant difference in outcomes between patients who received ACI alone versus those who received concomitant TTO. Of note, this series is subject to selection bias becasue patients receiving realignment had maltracking or instability not present in patients receiving ACI alone. ${ }^{17}$

Bipolar lesions of the PF joint represent advanced pathology of cartilage degradation. Meric et al. ${ }^{16}$ notes that overall lesions sizes exceeding $31.8 \mathrm{~cm}^{2}$ are likely not amenable to restorative procedures. In such cases, patients may be exhibiting an irreversible progression toward osteoarthritis, underlying subchondral bone remodeling, and a catabolic, inflammatory cascade driven by the adjacent synovial tissue. ${ }^{11}$ An intermediate option may lie with isolated patellofemoral arthroplasty, with recent studies demonstrating a high rate of return to preoperative range of motion and patient reported outcomes. ${ }^{34-36}$ However, the rate of conversion to total knee arthroplasty ranges from $8.0 \%$ to $18.1 \%$ within 5 years, and the results in younger, more active patient subsets remains unclear. ${ }^{37}$ Alternatively, PF arthroplasty is an alternative consideration. Long-term data suggest that this procedure is inevitably an intermediate procedure as tibiofemoral degeneration is reported to occur in $25 \%$ of patients, and implant loosening is relatively uncommon. ${ }^{38,39}$ Surgical decision-making should be informed through a shared decision-making process, and the ultimate treatment must be made on the basis of a holistic assessment of individual patient factors and expectations.

\section{Limitations}

The present article is limited by its inability to complete a meta-analysis because of the high heterogeneity and limited set of Level IV case studies included, which precluded pooling of data. Articles had varying

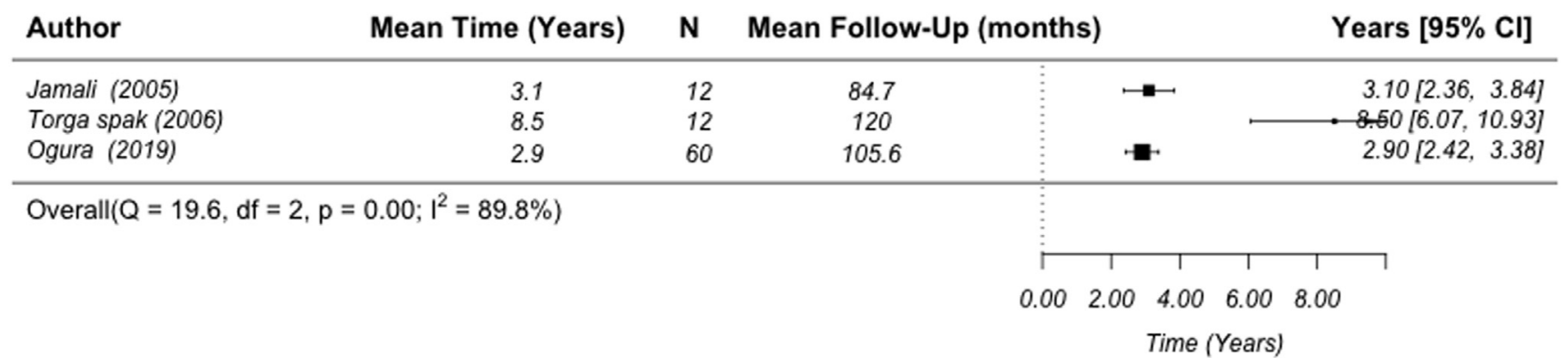

Fig 4. Time to failure of operative management of bipolar patellofemoral lesions. N, refers to total number of bipolar cases; Q, Cochran's Q-statistic for heterogeneity; df, degrees of freedom; $\mathrm{p}$, statistical significance test for heterogeneity; $\mathrm{I}^{2}$, measure of heterogeneity. 
indications, surgeries performed, lesion sizes treated, and concomitant procedures performed, which may bias results, along with the nonrandomized methodology of the studies. Additionally, all articles were case series, which lack any control group. Therefore it is unclear whether treatment of bipolar lesions truly altered a patient's course of disease. The studies included did not use a consistent definition for failure or time to failure, which made drawing conclusions from our "rate of failure" outcome measure challenging. Furthermore, use of a funnel plot may be biased in reviews with fewer than 10 studies.

\section{Conclusion}

From the available data, established cartilage restoration procedures may provide favorable patientreported function, avoidance of secondary surgery, and joint preservation in at least $80 \%$ of patients at short- to mid-term follow-up.

\section{References}

1. Flynn TW, Soutas-Little RW. Patellofemoral joint compressive forces in forward and backward running. J Orthop Sports Phys Ther 1995;21:277-282.

2. Astur DC, Arliani GG, Binz M, et al. Autologous osteochondral transplantation for treating patellar chondral injuries: evaluation, treatment, and outcomes of a two-year follow-up study. JBJS 2014;96:816-823.

3. Gillogly SD, Arnold RM. Autologous chondrocyte implantation and anteromedialization for isolated patellar articular cartilage lesions: 5-to 11 -year follow-up. Am J Sports Med 2014;42:912-920.

4. Minas T, Bryant T. The role of autologous chondrocyte implantation in the patellofemoral joint. Clin Orthop Relat Res 2005;436:30-39.

5. Hinckel BB, Pratte EL, Baumann CA, et al. Patellofemoral cartilage restoration: a systematic review and metaanalysis of clinical outcomes. Am J Sports Med 2020;48: 1756-1772.

6. Stefanik JJ, Guermazi A, Roemer FW, et al. Changes in patellofemoral and tibiofemoral joint cartilage damage and bone marrow lesions over 7 years: the Multicenter Osteoarthritis Study. Osteoarthr Cartil 2016;24:1160-1166.

7. Kapoor M, Martel-Pelletier J, Lajeunesse D, Pelletier J-P, Fahmi H. Role of proinflammatory cytokines in the pathophysiology of osteoarthritis. Nat Rev Rheumatol $2011 ; 7: 33$.

8. Gowd AK, Cvetanovich GL, Liu JN, et al. Management of chondral lesions of the knee: analysis of trends and shortterm complications using the National Surgical Quality Improvement Program Database. Arthroscopy 2019;35: 138-146.

9. Chui K, Jeys L, Snow M. Knee salvage procedures: the indications, techniques and outcomes of large osteochondral allografts. World J Orthop 2015;6:340.

10. Cavendish PA, Everhart JS, Peters NJ, Sommerfeldt MF, Flanigan DC. Osteochondral allograft transplantation for knee cartilage and osteochondral defects: a review of indications, technique, rehabilitation, and outcomes. JBJS Rev 2019;7(6):e7.

11. Giannini S, Buda R, Ruffilli A, et al. Failures in bipolar fresh osteochondral allograft for the treatment of end-stage knee osteoarthritis. Knee Surg Sports Traumatol Arthrosc 2015;23: 2081-2089.

12. Jamali AA, Emmerson BC, Chung C, Convery FR, Bugbee WD. Fresh osteochondral allografts: results in the patellofemoral joint. Clin Orthop Relat Res 2005;437: 176-185.

13. Torga Spak R, Teitge RA. Fresh osteochondral allografts for patellofemoral arthritis: long-term followup. Clin Orthop Relat Res 2006;444:193-200.

14. Minas T, Gomoll AH, Solhpour S, Rosenberger R, Probst C, Bryant T. Autologous chondrocyte implantation for joint preservation in patients with early osteoarthritis. Clin Orthop Relat Res 2010;468:147-157.

15. Vasiliadis HS, Lindahl A, Georgoulis AD, Peterson L. Malalignment and cartilage lesions in the patellofemoral joint treated with autologous chondrocyte implantation. Knee Surg Sports Traumatol Arthrosc 2011;19:452-457.

16. Meric G, Gracitelli GC, Görtz S, De Young AJ, Bugbee WD. Fresh osteochondral allograft transplantation for bipolar reciprocal osteochondral lesions of the knee. Am J Sports Med 2015;43:709-714.

17. Ogura T, Bryant T, Merkely G, Minas T. Autologous chondrocyte implantation for bipolar chondral lesions in the patellofemoral compartment: clinical outcomes at a mean 9 years' follow-up. Am J Sports Med 2019;47: 837-846.

18. Farr J. Autologous chondrocyte implantation improves patellofemoral cartilage treatment outcomes. Clin Orthop Rel Res 2007;463:187-194.

19. Gomoll AH, Gillogly SD, Cole BJ, et al. Autologous chondrocyte implantation in the patella: a multicenter experience. Am J Sports Med 2014;42:1074-1081.

20. Yabumoto H, Nakagawa Y, Mukai S, Saji T. Osteochondral autograft transplantation for isolated patellofemoral osteoarthritis. Knee 2017;24:1498-1503.

21. Mirzayan R, Charles MD, Batech M, Suh BD, DeWitt D. Bipolar osteochondral allograft transplantation of the patella and trochlea. Cartilage 2020;11:431-440.

22. Slim K, Nini E, Forestier D, Kwiatkowski F, Panis Y, Chipponi J. Methodological index for non-randomized studies (MINORS): development and validation of a new instrument. ANZ J Surg 2003;73:712-716.

23. DerSimonian R, Laird N. Meta-analysis in clinical trials revisited. Contemp Clin Trials 2015:45:139-145 (Pt A).

24. Egger M, Davey Smith G, Schneider M, Minder C. Bias in meta-analysis detected by a simple, graphical test. BMJ 1997;315(7109):629-634.

25. Niemeyer P, Steinwachs M, Erggelet C, et al. Autologous chondrocyte implantation for the treatment of retropatellar cartilage defects: clinical results referred to defect localisation. Arch Orthop Trauma Surg 2008;128: $1223-1231$.

26. Zarkadis NJ, Belmont PJ, Zachilli MA, et al. Autologous chondrocyte implantation and tibial tubercle osteotomy for patellofemoral chondral defects: improved pain relief and occupational outcomes among US Army servicemembers. Am J Sports Med 2018;46(13):3198-3208. 
27. Melugin HP, Bernard CD, Camp CL, Saris DB, Krych AJ. Bipolar cartilage lesions of the knee: a systematic review of techniques, outcomes, and complications [published online June 16, 2019]. Cartilage. doi: 1947603519855761.

28. Rue J-PH, Colton A, Zare SM, et al. Trochlear contact pressures after straight anteriorization of the tibial tuberosity. Am J Sports Med 2008;36:1953-1959.

29. Beck PR, Thomas AL, Farr J, Lewis PB, Cole BJ. Trochlear contact pressures after anteromedialization of the tibial tubercle. Am J Sports Med 2005;33:1710-1715.

30. Chahla J, Hinckel BB, Yanke AB, et al. An expert consensus statement on the management of large chondral and osteochondral defects in the patellofemoral joint. Orthop J Sports Med 2020;8(3):2325967120907343.

31. Pascual-Garrido C, Slabaugh MA, L'Heureux DR, Friel NA, Cole BJ. Recommendations and treatment outcomes for patellofemoral articular cartilage defects with autologous chondrocyte implantation: prospective evaluation at average 4-year follow-up. Am J Sports Med 2009;37:33S-41S (Suppl 1).

32. Trinh TQ, Harris JD, Siston RA, Flanigan DC. Improved outcomes with combined autologous chondrocyte implantation and patellofemoral osteotomy versus isolated autologous chondrocyte implantation. Arthroscopy 2013;29:566-574.
33. Peterson L, Vasiliadis HS, Brittberg M, Lindahl A. Autologous chondrocyte implantation: a long-term follow-up. Am J Sports Med 2010;38:1117-1124.

34. Fredborg C, Odgaard A, Sørensen J. Patellofemoral arthroplasty is cheaper and more effective in the short term than total knee arthroplasty for isolated patellofemoral osteoarthritis: cost-effectiveness analysis based on a randomized trial. Bone Joint J 2020;102-B(4):449-457.

35. Joseph MN, Achten J, Parsons NR, Costa ML, PAT Trial Collaborators. The PAT randomized clinical trial. Bone Joint J 2020;102-B:310-318.

36. Odgaard A, Madsen F, Kristensen PW, Kappel A, Fabrin J. The Mark Coventry Award: Patellofemoral arthroplasty results in better range of movement and early patientreported outcomes than TKA. Clin Orthop Relat Res 2018;476:87-100.

37. Lewis PL, Tudor F, Lorimer M, et al. Short-term revision risk of patellofemoral arthroplasty is high: An analysis from eight large arthroplasty registries. Clin Orthop Rel Res 2020;478:1222-1231.

38. Lonner JH. Patellofemoral arthroplasty. JAAOS 2007;15: 495-506.

39. Kooijman H, Driessen A, Van Horn J. Long-term results of patellofemoral arthroplasty: a report of 56 arthroplasties with 17 years of follow-up. J Bone Joint Surg Br 2003;85: 836-840. 